\title{
Effect of Quality of Work Life to Employees' Job Performance in Private Clinics in Ho Chi Minh City, Vietnam
}

\author{
Le Minh Trung, Dang Duy Phuong
}

\begin{abstract}
Among sources of an organization, human resource is regarded as the most important one. Therefore, factors affecting to employees' job performances have to be studied, especially in private clinics, since employees working in these clinics are persons directly taking care of patients. This empirical study will discuss about the Quality of Work Life with characteristics of Working environment (WKE); Facilities (FAC); Promotion policies (PMP); Leadership style (LDS) which are proposed to affect positively to Employee Job Performance (EJP). In addition, the study collected 202 good samples in the private clinics in Ho Chi Minh City to analyze this issue. After analyzing the data and the results showed that, factor affecting most and strongly to EJP was factor LDS with $\beta$ $=0.330$; the second factor affecting positively and strongly to EJP was FAC with $\beta=0.230$; the third factor affecting strongly to EJP was PMP with $\beta=0.195$ and the final one was WKE with 0.166. Besides, basing on this finding, the author suggested managers of private clinics as well as scholars refer this study to orient their strategies or use it as database to improve employees' performance in the internationalized context in the new era and the severe competition between enterprises.
\end{abstract}

Index Terms - Private Clinic, Quality of work life, Working environment, Leadership skill, Employees' job performance.

\section{INTRODUCTION}

In the era of severe competition among organizations, quality of working environment for human resources plays an important role in business organizations, which is also for private clinics. Vo et al. (2015) stated that human resource was one of the most important factors affecting one country's development and the survival of an organization. Besides, many studies showed that there were many factors affecting clients' purchasing decisions and enterprises had to compete against their rivals to be survival in the tremendous competitive market (Vuong, 2015). Therefore, in order for firms to provide good services for clients and get their loyalty, employees' performance is quite important as employees are the persons who directly serve clients. In addition, employees' mutual relationships were determined to be crucial to their overall wellbeing and performance ratings at work (Tran et al., 2018). Besides, in some decades ago, over three billion employees worldwide had to face with a serious problem in every company and that became an essential part of every working field (Mai and Vu, 2016). Therefore, if the

Le Minh Trung, University of Medicine Pham Ngoc Thach, Ho Chi Minh City, Vietnam

Dang Duy Phuong, Vietnam working environment is not good, it will affect employees' productivity and firm's performance. Mai and $\mathrm{Vu}$ (2016) presented that stress could have a positive influence on employees only with a certain amount at which an employee can handle; however, mostly it exceeded the tolerable limits and had a negative effect on employees. As a result, organizations have to create a professional and comfort working environment for employees, especially for healthcare organization since it is the place to take care of human beings' health.

In addition, some scholars stated that a high quality of work life (QWL) was considered as an integral factor for many organizations to achieve their high performance and growth (Vo et al., 2015). Besides, QWL is regarded as a new concept in Vietnam as there have not been any studies for this issue until now (Vo et al., 2015). Therefore, in the new era, in order for employees working effectively and serving clients with better services, it is necessary for organizations to create and build a more professional working environment. Besides, managerial practices in the healthcare sectors are said to face considerable challenges to improve medical staffs' performance in the fast growing conditions of healthcare industry (Tran et al., 2018) so that evaluating factors influencing medical staffs' performance become vital for scholars and hospital executives (Tran et al., 2018). Therefore, quality of work life (QWL) plays a key role to bring staff performance in private clinics as this is a special service type to examine and treat patients so that it needs to have a professional and exact working environment but comfort for employees to serve patients effectively and safely. From the real situations, this empirical study will investigate the effect of Quality of Work Life on The Employee Job Performance in Private Clinics in Ho Chi Minh City, Vietnam. In addition, this paper will help researchers and managers have a general view for administrative knowledge for supplemental studies as well as apply in management of private clinics.

\section{REVIEW OF LITERATURE}

\section{A. Quality of work life:}

Some previous studies found out a variety of factors affecting employees' job performance such as working environment, interpersonal relationships, job satisfaction, commitment, leadership styles, etc (Kacmar et al., 2009; Platis et al., 2015; Manning et al., 2016; Tran et al., 2018). Besides, quality of work life was considered as employees' 
need satisfaction which derived from an interaction of staffs' needs towards organization's related resources to meet theirs (Efraty and Sirgy, 1990; Vo et al., 2015).

In addition, a good and healthy working environment is said to have a lot of interests since it attached with employees' benefits (Ragins and Dutton, 2007; Tran et al., 2018) as well as achieving the organization's goals (Dutton and Heaphy, 2003; Tran et al., 2018). Therefore, quality of work life in organizations will help employees have a comfortable spirit, motivation to work as well as even work more effectively.

Morever, Mai et al. (2016) introduced some practical studies presenting the mutual relationships between factors to develop career, team spirit, relationship at work, compensation and benefit, working environment, job stress and employees' job satisfaction as well as employees' performance to raise up the awareness of business organizations which are in hospitality industry in Ho Chi Minh City about the order level of these factors impacting on their employees' job satisfaction and job performance.

According to Hsu and Kernohan (2006); Vo et al. (2015), when examining QWL, they identified differences of QWL dimensions such as security, autonomy, organization and interpersonal relations, workers' involvement and commitment, working conditions, opportunities for personal growth, quality of work life feelings, job stress, union-management relations and belief in management's support. It can be seen that there are many issues towards QWL. However, the basic characteristics of QWL are related to working environment, facilities, promotion policies, and leadership style which will create a comfort workplace to help employees work more effectively.

\section{B. The relationship between Quality of Work Life and The} Employee Job Performance:

Between Quality of Work Life and Employee Job Performance, there is a cause and effect relationship. Besides, the relationship between employees and their supervisor is regarded as a main aspect towards employees' connection to the organization, and employees' behaviors are affected by their supervisors' managerial style (Mai and Vu, 2016). In addition, the relationship between employees and their colleagues becomes essential to the firm's success as well as helps employee complete not only their work goals but also the firm's goals (Mai and Vu, 2016).

Leaders of enterprises gradually recognize the importance of workplace balance with relaxed element and comfort for employees in the organization. For employees, their salary has not been the most important factor to have a strong attachment to the firm. It is easy to understand that everyday employees work in the firm for 8 hours or even more and their time in the firm may be longer than at home so that they consider the firm as their second home. Therefore, if building a good working environment in which all members of the firm have conditions to develop their competence and their unique skills, creating the excitement at work, it will help employees work more effectively. Besides, many methods are used to improve employees' performance such as by proper and standardized facilities, awards to motivate employees, and enhancing working environments (Auliyah and Artaya, 2019). In addition, the more positive employees' relationships at work are, the more enjoyable the workplace becomes as well as better satisfaction and their engagement (Mai and Vu, 2016). Therefore, job performance is related to some factors such as working environment, facilities, promotion policy, and leadership competence, especially for private clinics. If quality of work life is good, employees will work effectively and satisfy patients.

According to Baumeister and Leary (1995), employees are suggested to create and maintain positive relationships with each other at work. Therefore, in order for quality of work life to be good, it not only needs to have good facilities but the leadership style and communication skills have to be also friendly with each other. Effective communication is one of the good components of relationship among staff (Mai and $\mathrm{Vu}, 2016)$. When managers have the democratic leadership style, employees will feel respected and they perform with all their hearts. Besides, when employees feel comfortable with their working environment, they will perform more effectively and enjoy the firm's working process better than those who feel uncomfortable (Mai and $\mathrm{Vu}, 2016$ ). As a result, the basic elements of quality of work life such as promotion policy, facilities, working environment, and leadership style are proposed to affect employees' job satisfaction. In the market's competition nowadays, private clinics have to pay attention and have basic strategies to build a good working environment for employees to serve patients. When employees are satisfied, they will serve patients well and create the reputation for the clinic so that brand name of the private clinic will have a good reputation as well as increase its competitive competence in the severe competition era nowadays.

\section{Working environment}

There are many concepts for working environment in different contexts. According to Mai and Vu (2016), working environment is defined as a physical geographical location as well as the surroundings of a workplace such as a factory site or an office building. A positive working environment will make employees excited when going to work and they remain this motivation all day. In addition, for more particular interests, the ways in working environment may influence the received information and resources derived from two primary sources of relationships were discussed between supervisors and colleagues (Tran et al., 2018). Meanwhile, the working culture in private clinics is very important. It always creates belief for employees working in that environment to work comfortably and effectively. The culture in private clinics is also a string connecting members within an organization, creating the same speech among members, increasing the competitive competence among other private clinics, especially in the integrating context when having many international clinics operated in Vietnam.

In addition, in health management, the specific, sufficient and exact information about employees' tasks from their working environment will affect or may lead to identify incorrect reality from bad working environment which also affect the employees' action plan. Employees' thoughts and expectations are not individuals' issues, but also the concern of colleagues and managers. Therefore, medical staffs play a 
decisive role in healthcare service, an essential need of citizens, and the first target of managers in private clinics. When having proper methods with needs and satisfaction with expectation, employees will have peace of mind, activeness and compete fairly at work, which create positive influence for survival and development of medical clinics. Therefore, the author supposed the first hypotheses as following:

H1: There is a significant relationship between working environment and Employee Job Performance.

\section{Facilities}

Facilities which are good at quantity and quality will create conditions for employees to serve more perfectly and more professionally to satisfy clients better. According to Auliyah and Artaya (2019), facilities are said to become supporting facilities in the physical activity of an organization or even are used in normal corporate's activities as well as having a relatively permanent useful life period and providing benefits for the future. Therefore, facilities are considered as the important factors to contribute for the good quality of work life leading to the employees' job satisfaction and performance.

Moreover, in private clinics with services for diagnosing and testing diseases, human resource factor plays an important role in providing services and affects directly to patients' feeling in the process of using that service. Therefore, investing in human beings to improve service quality is the direct investment for enhancing service quality of private clinics. In other words, facilities can be understood as working conditions such as air-conditioners, computers, and medical machines to serve for diagnosing and treating diseases, which affect employees' performance. In addition, facilities are one of elements creating quality of work life for staff in the private clinics, which will create working conditions for employees more effectively and professionally. Therefore, the author supposed the second hypothesis as following:

H2: There is a significant relationship between Facilities and Employee Job Performance.

\section{Promotion policies}

Owning a good source of human resource and they are always ready to complete their assigned tasks is any organization's expectation. In order to identify possibility for long-term commitment to an organization, welfare policy is always considered carefully by employees, and it is also an important factor of quality of work life for staff in private clinics. This is evaluated as one of important elements to measure attraction of private clinics so that employees will decide to have a strong attachment to their work or not. In addition, career development is also said to provide beneficial opportunities for employees when joining in professional training and other types of professional development in order to achieve their advanced skills as well as taking greater responsibility at work, improving their status or earning higher income, all of which are aimed to develop their career (Mai et al., 2016). Moreover, organizations will become more effective and efficient if they have their professional employees who know how to use their skills and abilities in workplace to handle tasks well as well as complete their roles successfully in order to develop their organizations (SHRM, 2013; Mai et al., 2016). Therefore, promotion policies are welfare policies for employees to work and it is not only important for any organizations but also for private clinics. Creating the promotion policy will help employees have peace in mind to work effectively and serve patients better.

In addition, welfare policy based on working performance is not only focused on salary, which means it is not necessary to increase salary, rewards when staff have good performance, but it is also a treating mechanism based on performance with rewards that have spirit values or creating conditions for employees in private clinics to have new experience so that they will be active in adjusting their behaviors, life style, and supporting their colleagues more. The final result is to improve the common performance in the organization. In addition, compensation and benefit are said to refer to all forms of financial returns, tangible services and benefits that all employees could receive as an important and essential part in the working environment (Mai et al., 2016). Besides, payment may be implemented by cash (wages, merit increases, incentives, cost of living adjustments, etc.) or indirectly through some benefits and services (pensions, health insurance, paid time off) (Milkovich and Newman et al., 2008; Mai et al., 2016). Therefore, promotion policies such as promotion at work, increased salary, and other welfare policies for employees in private clinics are vital factors to satisfy employees and will help them dedicate and work more effectively. As a result, it will help private clinics develop stably and more sustainably. From the above analysis, the auhor supposed the third hypothesis as following:

H3: There is a significant relationship between Promotion policies and Employee Job Performance.

\section{Leadership style}

One of the most important factors is the working atmosphere, and the relationship between leader with employees and employees with each other is an important factor of quality of work life towards employee performance in private clinics. In order to create the friendly working environment, private clinics have to build their clear regulations for the limited rights, each individual's responsibility. Meanwhile, leadership style is the working motivation for employees and creates a comfortable environment to staff. Leadership, one of the most researched topics by many scholars, is equally considered as a great importance for any organizations as well as for employees (Memon, Khalid, 2014).

Leadership style is related a process, in which an individual will be influenced by manager's thoughts, attitudes, and behaviors. A leader will set a direction for the firm, helping employees see what lies ahead, visualizing what the leader might achieve and how to achieve it, and encouraging or inspiring his or her subordinates (Quinn, 2005; Memon and Khalid, 2014). Moreover, effectiveness of leadership can mostly be measured through employees' performance and organizational effectiveness or growth (Memon, Khalid, 2014). In addition, Sugianingrat and Sarmawa (2017) stated that motivation can be said to impel employees to work hard 
in order to achieve the organization's goals. The democratic leadership style will help staff in private clinics self-control in their tasks and have responsibilities with their duties. According to Sugianingrat and Sarmawa (2017), motivation of work is regarded as one of key factors affecting the improvement of employees' performance so that it will also improve the teamwork competence and connect divisions effectively. Teamwork is explained by individuals' collaboration in a group together to gain certain specialization in capacities, abilities, knowledge and skills to perform task as well as being responsible for the outcomes at the same time that their tasks were conducted (Manzoor et al., 2011; Mai et al., 2016).

From the above analysis, it can be said that leadership style affects much to employees' performance. When leaders of the organization manage by democratic style, giving the authority and responsibilities for employees, they will be utterly dedicated to working, more loyalty with the organization, and bring back higher performance for assigned tasks to the organization or even for the private clinics. Therefore, leadership style is an important factor to enhance employees' performance. As a result, the author supposed the fourth hypothesis as following:

H4: There is a significant relationship between leadership style and Employee Job Performance.

\section{Employee Job Performance}

Employees are the most valuable assets of each organization and the basic foundation for firms to build and develop. Therefore, organizations have to have proper policies to help employees develop completely, have peace of mind to dedicate to the organization so that it also helps the organization develop sustainably and dedicate for society. According to Vuong and Rajagopal (2017), staffs' satisfaction and commitment affected significantly to business results of organizations. If staffs do not satisfy with their working conditions, it will lead to lack of dedication, creativity, and low efficiency in working. As a result, staff satisfaction is so important to any organizations, even for clinics. The greatest target of current private clinics is to satisfy patients, not only to treat patient well to be out of disease. Meanwhile, staff is the important factor as they are the persons who contact and serve patients directly. The staffs in private clinics are group of doctors, technicians, experts, nurses, etc. According to Mai et al. (2016), good performance of employees and productivity growth are important factors to stabilize the national economy so that it can improve the better living standards, growing up higher wages and increasing the available goods for consumers. Therefore, employees' job performance is the basic strategy and needed to improve in enterprises, even in private clinics.

Service for diagnozing and treating diseases is one of necessary services to take care human beings' health so that employees in clinics have to work effectively to ensure patients' safety and private clinic's reputation. Job performance is the behaviors at work which are related to organizational observable, scorable evaluations (Viswesvaran and Ones, 2000; Mai and Vu, 2016). In addition, job performance is considered as an activity that individuals have to complete the assigned task successfully
(Mai and Vu, 2016). It can be said that Employee Job Performance is the key factor for development and survival of private clinics not only in Vietnam, but also in HCMC in particular.

\section{METHODOLOGY}

\section{A. Research methodology}

In the first stage, the author reviewed the main elements affecting employees' job satisfaction. After studying, the author presented 4 factors affecting to employees' job satisfaction such as working environment, facilities, promotion policies, and leadership style. The 4 prediction variables will be expected to affect employees' job satisfaction.

In the second stage, the author would collect data from employees, managers, doctors, nurses in private clinics in HCMC. The data was collected by the convenient method and 202 good samples were collected for analysis. The author also used 5-point Likert scale for analyzing the observed variables to explain the above factors. The scale was ranged from 1 (Completely disagree) to 5 (Completely agree).

The third stage would be implemented by analyzing the reliability of scale, EFA. After satisfying the coefficients of scales and standards for analyzing factors, the author continued to analyze the Multivariate Multiple Regression to check regression values.

\section{B. Scale for factors and observed variables of each factor}

\section{Working environment (WKE)}

WKE1: The working environment in this clinic is so comfortable when working.

WKE2: There is a fair share in this clinic.

WKE3: There is a support from colleague when working in this clinic.

WKE4: Working environment in this clinic creates employees' excitement.

WKE5: Working environment in this clinic is fairly professional.

\section{Facilities (FAC)}

FAC1: This clinic always invests in modern machines to serve patients.

FAC2: Air-conditioners and working conditions in this clinic are fairly good.

FAC3: In this clinic, the management board supplies enough facilities for tasks.

FAC4: This clinic is clean with necessary facilities.

\section{Promotion policies (PMP)}

PMP1: There are many good opportunities for employees to promote in this clinic.

PMP2: Employees will have many benefits such as insurance, traveling, etc. in this clinic.

PMP3: Staffs in this clinic will have their salary increased by each period.

PMP4: Staffs in this clinic are always trained to improve skills and knowledge.

PMP5: Staffs in this clinic are encouraged to participate in workshops to improve visions. 


\section{Leadership style (LDS)}

LDS1: Employees receive compliments, encouragement from the senior when performing their tasks well.

LDS2: Employees have self-control at work.

LDS3: Leader manages the clinic with democratic spitit.

LDS4: Leader encourages employees' creativity.

LDS5: Staffs feel to have motivations and promotions when working in this clinic.

\section{Employee Job Performance (EJP)}

EJP1: I always meet the assigned tasks from my manager.

EJP2: I always complete my job efficiently and effectively.

EJP3: I am utterly dedicated to work in this pravite clinic without tiredness.

\section{CONCEPTUAL RESEARCH FRAMEWORK:}

$\mathrm{Y}=\beta \mathrm{o}+\beta 1 * \mathrm{X} 1+\beta 2 * \mathrm{X} 2+\beta 3 * \mathrm{X} 3+\beta 4 * \mathrm{X} 4+\sigma$

While Y= Employee Job Performance (EJP);

$\mathrm{X} 1=$ Working environment (WKE);

$\mathrm{X} 2=$ Facilities $(\mathrm{FAC})$;

$\mathrm{X} 3=$ Promotion policies (PMP);

$\mathrm{X} 4=$ Leadership style (LDS);

$\sigma=$ Error Term;

$\beta o=$ the intercept; $\beta 1, \beta 2, \beta 3$ and $\beta 4=$ the regression coefficients for the four dimensions of the IVs measures.

\section{RESULTS AND DISCUSSION}

\section{A. Result of analyzing the scale}

Table 1: Result of analyzing the reliability of scales

\begin{tabular}{|l|c|}
\hline Factors & $\begin{array}{c}\text { Cronbach's } \\
\text { Alpha }\end{array}$ \\
\hline Working environment (WKE) & .834 \\
\hline Facilities (FAC) & .772 \\
\hline Promotion policies (PMP) & .834 \\
\hline Leadership style (LDS) & .742 \\
\hline $\begin{array}{l}\text { Employee Job Performance } \\
\text { (EJP) }\end{array}$ & .738 \\
\hline
\end{tabular}

As presented above, the author analyzed coefficients of Cronbach's Alpha to test the reliability of scale and then removed variables with Corrected Item - Total Correlation < 0.3 , except for variables with Cronbach Alpha $\geq 0.7$. From the table 1, it can be seen that coefficients of Cronbach's Alpha of all factors are all $>0.7$ and factor loading $>0.3$. Therefore, the scales had reliability and were accepted for analysis.

\section{B. Result of EFA}

When analyzing factors, the author supposed two hypotheses:

Null hypothesis $\left(\mathrm{H}_{0}\right)$ : There is no relationship among variables.

Hypothesis 1a $\left(\mathrm{H}_{1 \mathrm{a}}\right)$ : There is a relationship among variables.
Table 2: Coefficients of KMO and Barlett's Test

\begin{tabular}{|l|c|c|}
\hline \multicolumn{3}{|c|}{ KMO and Bartlett's Test } \\
\hline \multicolumn{2}{|c|}{ Kaiser-Meyer-Olkin } \\
Measure of Sampling \\
Adequacy.
\end{tabular}

Result of KMO and Bartlett's Test in Table 2 showed that variables had a mutual relationship $(\mathrm{sig}=0.00<0.05$, rejecting $\mathrm{H}_{0}$, accepting $\mathrm{H}_{1 \mathrm{a}}$ ). Concurrently, $\mathrm{KMO}=0.910$ > 0.5 showed that analyzing factors to group variables together was proper and data was also suitable to analyze. In addition, all factors had Eigenvalues $>1$. The Average Variance Extracted with $58.900 \%>50 \%$ was met the requirement. With the principal components and Varimax by assigning the number of factors needing to be extracted, there were 4 factors extracted from observed variables. This showed that $58.9 \%$ of changes from the 4 extracted factors were explained by observed variables and values of observed variables explained the meaning of each factor.

Table 3: Rotated Component Matrix:

\begin{tabular}{|l|l|l|l|l|}
\hline \multicolumn{5}{|c|}{ Rotated Component Matrix } \\
\hline & \multicolumn{2}{|c|}{ Component } \\
\hline & 1 & 2 & 3 & 4 \\
\hline WKE4 & .723 & & & \\
\hline WKE1 & .722 & & & \\
\hline WKE2 & .702 & & & \\
\hline WKE5 & .694 & & & \\
\hline WKE3 & .652 & & & \\
\hline PMP3 & & .819 & & \\
\hline PMP2 & & .678 & & \\
\hline PMP4 & & .654 & & \\
\hline PMP1 & & .651 & & \\
\hline PMP5 & & .614 & & \\
\hline LDS1 & & & & \\
\hline FAC4 & & & .746 & \\
\hline FAC1 & & & .720 & \\
\hline FAC2 & & & .710 & \\
\hline FAC3 & & & .673 & \\
\hline LDS2 & & & & .794 \\
\hline LDS4 & & & & .629 \\
\hline LDS3 & & & & .612 \\
\hline LDS5 & & & & .595 \\
\hline $\begin{array}{l}\text { Extraction } \\
\text { Analysis. } \\
\text { Rotation } \\
\text { Normalization. Method: }\end{array}$ & & & & \\
\hline a. Rotation converged in 6 iterations. & \\
\hline
\end{tabular}


In Table 3, the result of EFA showed that scale was accepted and devided into 4 distinguished groups. Some variables of the components in the scale have the factor loadings $>0.3$. It showed that each factor had the distinguished value and each observed variable had the contributing values for meaning of each factor.

\section{Regression analysis}

Table 4: Evaluating the suitability of Multivariate Multiple Regression model:

\begin{tabular}{|l|l|l|l|l|}
\hline \multicolumn{2}{|l|}{ Model Summary $^{\mathbf{b}}$} & & Adjusted R Square & $\begin{array}{c}\text { Std. Estimate } \\
\text { Estor of the }\end{array}$ \\
\hline 1 & $\mathrm{R}$ & $\mathrm{R}$ Square & .557 & .34863 \\
\hline a. Predictors: (Constant), LDS, FAC, WKE, PMP & .566 & & \\
\hline \multicolumn{2}{|l}{ b. Dependent Variable: EJP }
\end{tabular}

Table 4 showed that value of coefficient $\mathrm{R}$ was $0.566>0.5$; therefore, this is a suitable model to evaluate the relationship between independent variables and dependent one. Besides, value of Adjusted R Square was 0.557. The built Linear Regression Model was suitable with data 55.7\%. In other words, 55.7\% of factor EJP were changed due to changes of independent factors such as Working environment (WKE), Facilities (FAC), Promotion policies (PMP), Leadership style (LDS) while $44.3 \%$ left was due to other factors.

Table 5: Result of regression weights:

\begin{tabular}{|c|c|c|c|c|c|c|c|c|}
\hline \multicolumn{9}{|c|}{ Coefficients $^{\mathrm{a}}$} \\
\hline \multirow{2}{*}{\multicolumn{2}{|c|}{ Model }} & \multicolumn{2}{|c|}{$\begin{array}{l}\text { Unstandardized } \\
\text { Coefficients }\end{array}$} & \multirow{2}{*}{$\begin{array}{l}\begin{array}{c}\text { Standardized } \\
\text { Coefficients }\end{array} \\
\text { Beta }\end{array}$} & \multirow[b]{2}{*}{$\mathrm{t}$} & \multirow[b]{2}{*}{ Sig. } & \multicolumn{2}{|c|}{ Collinearity Statistics } \\
\hline & & B & $\begin{array}{l}\text { Std. } \\
\text { Error }\end{array}$ & & & & Tolerance & VIF \\
\hline & $\begin{array}{l}\text { (Consta } \\
\mathrm{nt})\end{array}$ & .543 & .192 & & 2.824 & .005 & & \\
\hline & WKE & .148 & .057 & .166 & 2.595 & .010 & .538 & 1.860 \\
\hline & FAC & .216 & .055 & .230 & 3.950 & .000 & .648 & 1.543 \\
\hline & PMP & .183 & .062 & .195 & 2.937 & .004 & .501 & 1.995 \\
\hline & LDS & .325 & .062 & .330 & 5.250 & .000 & .557 & 1.794 \\
\hline
\end{tabular}

From the Table 5, it showed that all sig. values of factors were $<0.05$. Coefficient of VIF was $<2$ so that there was no phenomenon of multicollinearity. The coefficient $\beta$ of WKE was 0.166 , FAC was 0.230 , PMP was 0.195 and LDS was 0.330 .

Based on Table 5 and from analysis in the regression model, the Linear Regression Model of factors affecting EJP in private clinics in HCMC with standardized coefficients as followings:

$$
Y=0.543+0.166 * X_{1}+0.230 * X_{2}+0.195 * X_{3}+0.330 * X_{4}
$$
$+\sigma$.

Therefore, from the regression analysis, it can be said that Quality of Work Life with 4 factors such as Working environment (WKE), Facilities (FAC), Promotion policies (PMP), and Leadership style (LDS) affected positively to Employee Job Performance (EJP). The author suggested that private clinics in HCMC have strategy to improve the 4 mentioned factors in order to enhance employees' performances so that it will help patients have peace of mind to have treatment as well as improving private clinics' reputation in HCMC, Vietnam.

\section{CONCLUSION}

Based on the statistical analysis, it showed that factors with valuable scales all satisfied the reliability. When applying
EFA, all factors had the distinguished values while in a factor the observed variables satisfied contributions for each factor's meaning. The statistical coefficient had good values and there was no removed factor.

In addition, the proposed hypothesis was that 4 factors Working environment (WKE), Facilities (FAC), Promotion policies (PMP), and Leadership style (LDS) all affected Employee Job Performance (EJP) with all values of 4 factors with P-value $<0.05$ so that the proposed hypotheses all have the statistical meanings.

The regression result showed that the Quality of Work Life was presented by 4 factors affecting Employee Job Performance of private clinics in HCMC. In reality, for the private clinics in HCMC, the most affecting and strongest factor was Leadership style (LDS) with $\beta=0.330$; the second positively affecting factor was Facilities (FAC) with $\beta=$ 0.230 ; the third affecting factor was Promotion policies (PMP) with $\beta=0.195$ and the final one affecting strongly to Employee Job Performance was Working environment (WKE) with $\beta=0.166$.

From the findings, it can be said that in order to improve employees' performance in private clinics managers should pay attention to these above factors and apply this study to set up their plans. The administrators of private clinics have to improve the following basic issues: 
Firstly, the factor affecting strongly and positively to employees' performance was Leadership style so that administrators should develop and improve the managerial skills and create the working motivation for their employees. Administrators should manage the clinic with democratic style to create the positive spirit for staff to perform well. They should also turn over the authority to staff as well as inspire and encourage them in the working process.

Secondly, based on the findings, the second positive affecting factor to employees' performance was Facilities. Therefore, administrators should invest in good infrastructure by improving and upgrading facilities, machines for staff to work and serve patients. Infrastructure and medical facilities are one of important and decisive sources towards medical activities in order to meet the patients' needs for diagnosing and treating diseases in the severely competitive context nowadays. Therefore, each clinic should enhance facilities for staff to work and serve patients so that employees, nurses and doctors can use effectively to improve quality of healthcare services.

Thirdly, the findings showed that the third affecting factor to employees' performance was Promotion policies. Therefore, administrators and human resources department should have policies for employees' promotion, doctors, and nurses, etc. The management board should also have the periodic policy for increasing salary, rewards, traveling yearly for employees in order to build a professional working environment and promotion for them. As a result, it will help them work more enthusiastically and effectively.

Fourthly, the findings also showed that the positively and strongly affecting factor was Working Environment so that administrators should have a good, fair, democratic working environment to create the effective working conditions for doctors, nurses, and staff. That working environment has to be built by clear, specific, informative standards which are contributed by employees' opinions. Administrators also have to develop individuals' self-aware, and community's perception or duty. In addition, working culture in private clinics should be built with opening style, friendly and professional colleagues. Moreover, open-minded spirit at work will help staff have the comfortable mentality to develop their creativity and work better. Managers have to create unity in the internal clinic and prevent conflicts among staff. All employees have to support, learn from each other, unite and have responsibility to help each other at work. It is the key for each member to improve their expertise skill, working experience, which create teamwork's strength in order to develop their organization more and more. Besides, the senior always supports and creates working conditions for staff to develop their competence. From the above issues, those will be motivations for doctors, technicians, nurses, and staff to develop their latent potentials effectively to enhance clinics' reputation and competitive competence in the context of international integration in Vietnam.

\section{Limitation}

There are some limitations in this study:

The first limitation was due to limited time so that the author only collected samples in HCMC, therefore, it could not have the general view for improvement of working performance in
Vietnam. In future studies, researchers should have a larger scale of samples in other provinces in Vietnam to have a more objective view.

The second limitation was due to lack of samples so that the result was limited. Further studies should have larger samples to improve the exactness.

The third one was the convenient method for collecting data of the study, which is the non-probability method. This method only chose samples that the author could approach easily, and this limited for the study since the result could not be represented for the whole population.

The fourthly, the author only appraised generally the effect of factors towards employees' performance in private clinics in HCMC but not analyzing deeply solutions for those factors due to time limitation and costs for the study.

Finally, the author only analyzed 4 basic factors affecting Employees' Job Performance in private clinics in HCMC so that the study's result was limited since the latent factors such as working culture, salary, etc. Future studies can base on this study to investigate more other factors to have better and more perfect view.

\section{REFERENCES}

[1] Auliyah, A., Artaya, I. P., (2019). The Influence of Work Facilities, Rewards, and Work Environment on Improving Employee Performance at Quds Royal Hotel Surabaya. DOI: 10.13140/RG.2.2.11854.92484.

[2] Baumeister R.F., Leary M.R. (1995). The Need to Belong: Desire for Interpersonal Attachments as a Fundamental Human Motivation. Psychol. $\quad$ Bull. ;117: 497-529. doi: 10.1037/0033-2909.117.3.497.

[3] Dutton J.E., Heaphy E.D., (2003). Positive Organizational Scholarship: Foundations of a New Discipline.Berrett-Koehler; San Francisco, CA, USA, The Power of High-Quality Connections.

[4] Efraty D., and Sirgy MJ., (1990). The effects of quality of working life (QWL) on employee behavioral responses. Soc Indic Res. 22(1), 31-47.

[5] Factors affecting employee performance through a mediation of job satisfaction. An empirical study of hospitality industry in ho chi minh city, Vietnam. Journal of Science Ho Chi Minh City Open University, 2 (18), 49-62.

[6] Ferris G.R., Rogers L.M., Blass F.R., Hochwarter W.A., (2009) Interaction of Job/Limiting Pain and Political Skill on Job Satisfaction and Organizational Citizenship Behavior. J. Manag. Psychol. 24. doi: 10.1108/02683940910989002.

[7] Hsu MY., and Kernohan G., (2006). Dimensions of hospital nurses quality of working life. Journal of advanced nursing, 54(1), 120-31.

[8] Kacmar K.M., Collins B.J., Harris K.J., Judge T.A., (2009). Core Self-Evaluations and Job Performance: The Role of the Perceived Work Environment. J. Appl. Psychol, 94:1572-1580. doi: 10.1037/a0017498.

[9] Mai, N. K., and Vu, H. Y., (2016). Investigate the Effects of Job Stress on Employee Job Performance - A Case Study at Dong Xuyen Industrial Zone, Vietnam. International Journal of Trade, Economics and Finance, 7(2), 31-37.

[10] Mai, N. K., Nguyen, T. N. K., Pham, T. H., Nguyen, V. H. T., Nguyen, T. M. P., (2016).

[11] Manning J., (2016). The Influence of Nurse Manager Leadership Style on Staff Nurse Work Engagement. J. Nurs. Adm, 46:438-443. doi: 10.1097/NNA.0000000000000372.

[12] Manzoor S. R., Ullah H., Hussain M. and Ahmad Z. M. (2011). Effect of Teamwork on Employee Performance. International Journal of Learning \& Development, 1(1).

[13] Memon, Khalid. (2014). Effects of Leadership Styles on Employee Performance: Integrating the Mediating Role of Culture, Gender and Moderating Role of Communication. International Journal of Management Sciences and Business Research, 3, 63-80.

[14] Milkovich G. T. and Newman J. M. (2008). Compensation, 9th ed. McGrawHill Irwin.

[15] Platis C., Reklitis P., Zimeras S., (2015). Relation between Job Satisfaction and Job Performance in Healthcare Services. Procedia Soc. Behav. Sci, 175:480-487. doi: 10.1016/j.sbspro.2015.01.1226. 
[16] Quinn, M. D. (2005). Leadership: How to Lead, How to Live. Waltham, MA: MindEdge Press.

[17] Ragins B.R., Dutton J.E., (2007). Exploring Positive Relationships at Work: Building a Theoretical and Research Foundation. Lawrence Elarbum; NewYork, NY, USAPositive Relationships at Work, An Introduction and Invitation.

[18] Society for Human Resource Management (SHRM). (2013). Employee Job Satisfaction and Engagement: The Road to Economic Recovery.

[19] Sugianingrat, I. A. P. W., Sarmawa, I. W. G., (2017). Effect of work culture on employee performance with work motivation as mediator: study at nonstar hotel in denpasar-bali, Indonesia. International Journal of Economics, Commerce and Management, 5(12), 858-867.

[20] Tran, K. T., Nguyen, P. V., Dang, T., \& Ton, T. (2018). The Impacts of the High-Quality Workplace Relationships on Job Performance: A Perspective on Staff Nurses in Vietnam. Behavioral sciences (Basel, Switzerland), 8(12), 109. doi:10.3390/bs8120109.

[21] Viswesvaran, C., and Ones, D. S.., (2000). Perspectives on models of job performance. International Journal of Selection and Assessment, 8(4), 216-226.

[22] Vo, Q. T., Phan, T. G., Phan, T. D., Pham, d. 1., (2015). A Preliminary Study on the Effect of the Work-Related Quality of Life Indicators in Vietnamese Hospital: A Tool for Healthy, Healthcare Workplaces? Human Journals Research Article, 4(4), 79-94.

[23] Vuong, T. K., (2015). An Exploration of The Customer Behavioral Model For E- Marketing Strategy in Vietnam. Review of Management Innovation \& Creativity, 8(23), 97-104.

[24] Vuong, T. K., and Rajagopal, P., (2017). The Role of Contemporary Management and The Mediating Effect of Budgeting Process on The Performance of Small and Medium-Sized Enterprises (SMEs) in the Manufacturing Sector in Ho Chi Minh City- Vietnam. Asian Academic Research Journal of Social Sciences \& Humanities, 4(11), 1-27. 